\title{
Synthesis and Controlled Release Behavior of Biodegradable Polymers with Pendant Ibuprofen Group
}

\author{
Heying Deng, Jihua Song, Akoda Komlan Elom, Junlian Xu, Zhihui Fan, Chang Zheng, \\ Yumeng Xing, and Kuilin Deng
}

College of Chemistry \& Environmental Science, Hebei University, Baoding 071002, China

Correspondence should be addressed to Kuilin Deng; dkl369@hbu.edu.cn

Received 22 February 2016; Revised 7 April 2016; Accepted 28 April 2016

Academic Editor: Qinglin Wu

Copyright (c) 2016 Heying Deng et al. This is an open access article distributed under the Creative Commons Attribution License, which permits unrestricted use, distribution, and reproduction in any medium, provided the original work is properly cited.

\begin{abstract}
The continuous use of nonsteroidal anti-inflammatory drugs such as ibuprofen frequently leads to some serious side-effects including stomach ulcers and bleeding. In this paper, two kinds of new biocompatible polyesters (PIGB, PIGH) and polyesteramide (PIGA) comprising biodegradable components ( $L$-glutamic acid, 1,4-butanediol, and 1,6-hexanediol and 6-amino hexanol) and ibuprofen as pendant group have been prepared by the melting polycondensation. The chemical structures of the monomer and polymers are characterized by FTIR, ${ }^{1} \mathrm{H}$ NMR spectrum, GPC, and contact angle measurements. The drug loading of ibuprofen reaches very high level (35-37\%) for PIGB, PIGH, and PIGA carriers. The free ibuprofen molecules are released in vitro from polymer carriers in a controlled manner without a burst release, different from the release pattern observed in the other drugencapsulated systems. It is also found that the different hydrophilicity among PIGB, PIGH, and PIGA plays a key role in the timecontrolled release of ibuprofen. In addition, the viability of HeLa cells after $48 \mathrm{~h}$ of incubation reaches more than $100 \%$, indicating no cytotoxicity for PIGB, PIGH, and PIGA carriers.
\end{abstract}

\section{Introduction}

As a common nonsteroidal anti-inflammatory drug, ibuprofen is usually used to treat rheumatoid arthritis, osteoarthritis, psoriatic arthritis, and some pain/swellings in ankylosing spinal cord inflammation $[1,2]$. It has been reported that the half-life of ibuprofen in the blood is only 2.1 hours, so frequent use of this drug is needed by the patients [3]. However, some serious side-effects of ibuprofen could be initiated in various parts of the body (including disease part and nondisease part) as the drug use is used frequently $[4,5]$. For example, the patients would suffer from stomach ulcers, bleeding, and other pains with persistent usage of this drug.

In recent years, many developments in the drug delivery system have been focusing on the target release [6], controlled release [7], extended time of drug action [8], and so on. For ibuprofen, several methods for the preparation of drug carriers have been reported to solve the issues appearing in the direct use of drug. For example, polymer carrier of ibuprofen was prepared by the electrospinning of poly(trimethylene carbonate-co-e-caprolactone) [9]. The mono/multifilament sutures, made from ibuprofen-loaded poly(p-dioxanone), were fabricated through a molecular diffusion process using a swelling agent such as dichloromethane [10]. Molten ibuprofen was successfully loaded into the large spherical particles of amorphous microporous silica in the adsorption process [11]. Moustafa and coworkers also described a differential microemulsion polymerization technique to produce ibuprofen-entrapped nanoparticles, comprising copolymer from methyl methacrylate/hydroxyethyl methacrylate [12]. Compared with the traditional system, the design and preparation of these drug deliveries can reduce the sideeffects and effectively increase the duration time of drug. However, the main problems of the drug release systems still exist, that is, lower drug loading (less than 30\%), explosive release, and rapid drug release. A variety of drug carriers with low ibuprofen loading ratio were reported, using electrospun fibers [9], Pluronic mixture gels [13], copolymer membrane of ethylene vinyl acetate [14], and polymer-drug complexes [15]. The loading ratio of the drug 
is around $1-23 \%$. In addition, the widely used materials in the drug systems are usually acrylic/vinyl polymers with $\mathrm{C}-\mathrm{C}$ bond in their main-chains such as poly(methyl methacrylate/hydroxyethyl methacrylate) [12], polyethylene [16], poly(2-hydroxypropyl acrylate) [17], poly(hydroxyethyl methacrylate) [18], poly(methacrylic acid) [19], $\operatorname{poly}(N-$ isopropylacrylamide) [20, 21], and poly(vinylpyrrolidone) [22]. These polymers are not biodegradable or biocompatible in nature. Therefore, the used polymers would be retained in the human body after the drug is released, resulting in the potential harm and adverse effects [4].

Developing the biodegradable polymer as drug carriers can reduce organ toxicity, side-effects of drugs, and possible harms of residual polymers in body. Over the years, some researchers such as Jia and Kerr [23], Lin et al. [24], del Valle et al. [25], Rosario-Meléndez et al. [26], and Cantón et al. [27] have paid close attention to the investigation of drug carriers comprising biodegradable polymers. Kerr and coworkers described an ibuprofen carrier using a composite of biodegradable poly(lactic-co-glycolic acid) and $\mathrm{TiO}_{2}$ nanotubes with much improved mechanical strength and flexibility [23]. Lin et al. have prepared blend matrices for controlled drug release system using phosphorylcholinefunctionalized poly(caprolactone) with good biodegradability and biocompatibility [24]. del Valle et al. also fabricated ibuprofen-loaded porous matrices using biodegradable poly(ester amide) derived from sebacic acid, alanine, and 1,12dodecanediol [25]. In addition, the biodegradable polyglycolide is another widely used material for uniformly drug-loaded electrospun fibers [27].

In this paper, we made an attempt to prepare a new drug delivery carrier through grafting ibuprofen to glutamic acid-based, biodegradable polymers by chemical bond linkage. First, a new monomer with ibuprofen moiety was prepared, namely, $N$-2-methyl-4-(2-methyl propyl) phenylacetyl-glutamic acid (MMPPG). And then, the melting polycondensation of MMPPG was performed with 1,4-butanediol, 1,6-hexanediol, and 6-amino hexanol, respectively. Three resulting polymer carriers (two polyesters and polyester-amide) contain poly(N-2-methyl-4-(2-methyl propyl) phenylacetyl-glutamic acid-co-1,4-butanediol) (PIGB), poly(N-2-methyl-4-(2-methyl propyl) phenylacetyl-glutamic acid-co-1,6-hexanediol) (PIGH), and poly(N-2-methyl-4-(2methyl propyl) phenylacetyl-glutamic acid-co-6-amino-hexanol) (PIGA). PIGB, PIGH, and PIGA have many liable degradable groups (the esters or ester-amides) in their mainchain and their loading capacities of ibuprofen in the polymer carriers can reach up to $35-37 \%$. The release behaviors of ibuprofen from PIGB, PIGH, and PIGA carrier at $37^{\circ} \mathrm{C}$ and $25^{\circ} \mathrm{C}$ were investigated under the simulated physiological conditions (phosphate buffered saline). Also, the cell toxicity for PIGB, PIGH, and PIGA carriers was evaluated using the CCK-8 Cell Counting Kit assessment method in this paper.

\section{Materials and Methods}

2.1. Materials. L-glutamic acid was purchased from Tianjin Kermel Chemical Reagent Co. Ltd. and used as received. 1,4-Butanediol, 1,6-hexanediol, and 6-amino hexanol were obtained from Kermel Chemical Reagent Factory (Tianjin, China) with an analytical grade. Ibuprofen (2-methyl-4(2-methyl propyl) phenyl acetic acid) was received from Maya Reagent. Stannous octoate was from Western Asia Reagent. Deionized water was used for all aqueous sample preparations. High precision and ready-to-use dialysis bag (molecular weight cut-off (MWCO), $3500 \mathrm{Da}$ ) was purchased from Shanghai Green Bird, Shanghai Toscience Biotechnology Co., Ltd., China. Other reagents and solvents were of analytical grade and used without further purification. Moreover, HeLa cells were kindly supplied by Peking Union Medical College Hospital.

2.2. Methods. Vector 22 FTIR spectrometer was used to measure the infrared spectra of the monomer and polymers in the range of $400-4000 \mathrm{~cm}^{-1}$ with $\mathrm{KBr}$ pellets. ${ }^{1} \mathrm{H}$ NMR $(600 \mathrm{MHz})$ of the monomer and polymers were recorded at room temperature on a Bruker AVANCE III spectrometer with tetramethylsilane as an internal standard. A gel permeation chromatograph (GPC) system (Agilent 1200) was performed to determine the molecular weight $\left(M_{n}\right)$ and polydispersity index (PDI) of polymers. $N, N$ Dimethylformamide (DMF) with $0.1 \% \mathrm{LiBr}$ was selected as an eluting solvent and polystyrene was used as the molecular weight standard.

Contact angle measurements of polymers were performed at room temperature in air atmosphere by the sessile drop method using a goniometer DataPhysics OCA 15EC. The samples were prepared by melting method: first heating the sample on a glass plate at about $130^{\circ} \mathrm{C}$ and then cooling to room temperature for $1 \mathrm{~h}$ to cast sample films.. The films were kept at the desired temperature at least 30 min before the measurement. In the contact angle measurements, the angles were recorded 2 seconds after $2 \mu \mathrm{L}$ of water was dropped on the film. The final contact angle for each sample was calculated from the average value of five experimental results.

Cytotoxicity was evaluated using the CCK-8 Cell Counting Kit assessment in this investigation. The HeLa cells grew in a $\mathrm{CO}_{2}$ incubator with a humidified $5 \% \mathrm{CO}_{2}$ atmosphere at $37^{\circ} \mathrm{C}$ overnight. HeLa cells were maintained in RPMI-1640 (GIBCO) cell supernatant containing 10\% inactivated fetal bovine serum (FBS), $100 \mu \mathrm{g} / \mathrm{mL}$ penicillin, and $100 \mu \mathrm{g} / \mathrm{mL}$ streptomycin. For the assay, cells were plated at $5 \times 10^{5}$ cells/100 $\mu \mathrm{L} /$ well in a 96-well plate. The cells were preincubated with serum-containing regular medium, which contains sample $(0.01 \mu \mathrm{g} / \mathrm{mL}, 0.1 \mu \mathrm{g} / \mathrm{mL}, 1.0 \mu \mathrm{g} / \mathrm{mL}, 10 \mu \mathrm{g} / \mathrm{mL}$, and $100 \mu \mathrm{g} / \mathrm{mL})$ at $37^{\circ} \mathrm{C}$ for $48 \mathrm{~h}$. CCK-8 solutions $(10 \mu \mathrm{L})$ were added to each well, followed by incubation at $37^{\circ} \mathrm{C}$ for $1 \mathrm{~h}$. The medium was removed and $100 \mu \mathrm{L}$ of acidulated isopropyl alcohol was added to each well to dissolve the purple crystals. The plate was read for absorbance at $450 \mathrm{~nm}$.

In this study, we prepared a series of phosphate buffer solution of ibuprofen $(\mathrm{pH}=7.6)$ with the concentration including $10 \mu \mathrm{g} / \mathrm{mL}, 5 \mu \mathrm{g} / \mathrm{mL}, 2 \mu \mathrm{g} / \mathrm{mL}, 1 \mu \mathrm{g} / \mathrm{mL}$, and $0.5 \mu \mathrm{g} / \mathrm{mL}$ using a stepwise dilution method. A working curve was plotted using the maximum absorption (at $220 \mathrm{~nm}$ ) as $Y$ value and the concentrations of ibuprofen as $X$ value. The relationship between the absorption and the concentration 
of ibuprofen was obtained by the linear fitting. The equation is as follows: $Y=0.0557 X+0.0399(Y$ : absorbance, $X$ : concentration, and the linearly dependent coefficient $R=$ 0.9986). The release of ibuprofen from PIGA, PIGB, and PIGH carrier was studied at $37^{\circ} \mathrm{C}$ and $25^{\circ} \mathrm{C}$ under the simulated physiological conditions ( $\mathrm{PBS}, \mathrm{pH}=7.4$ ). Triplicate samples of each polymer (about $50.0 \mathrm{mg}$ powder) were placed in $20 \mathrm{~mL}$ vials together with $10 \mathrm{~mL}$ PBS under agitation $(60 \mathrm{rpm})$. After predetermined release time, the samples were centrifuged at $2000 \mathrm{rpm}$ for $6 \mathrm{~min}$. The clear solution was collected and replaced with the fresh PBS $(10 \mathrm{~mL})$ for the subsequent release study. The amount of released ibuprofen is calculated by the absorbance at $220 \mathrm{~nm}$ according to the working curve.

\subsection{Preparation of Monomer and Polymers}

2.3.1. Preparation of 2-Methyl-4-(2-methyl propyl) Phenylacetyl Chloride. 3.0 g 2-methyl-4-(2-methyl propyl) phenylacetic acid (ibuprofen) was added to a $100 \mathrm{~mL}$ round bottom flask with stirring. In the ice bath, the reaction system was cooled for $10 \mathrm{~min}$ and $10 \mathrm{~mL}$ thionyl chloride was then introduced into the reaction system. A large number of bubbles were generated and overflew from the flask. After 20 min reaction, the reaction system was changed into heating step and refluxed at about $65-75^{\circ} \mathrm{C}$ until no more bubbles were generated again in the flask. Lastly, the excess thionyl chloride was completely removed by rotating evaporation to get targeted compound, 2-methyl-4-(2-methyl propyl) phenylacetyl chloride.

2.3.2. Synthesis of N-2-Methyl-4-(2-methyl propyl) Phenylacetyl-Glutamic Acid (MMPPG). In a $100 \mathrm{~mL}$ flask, $3.26 \mathrm{~g} \mathrm{2-}$ methyl-4-(2-methyl propyl) phenylacetyl chloride was dissolved in $10 \mathrm{~mL}$ anhydrous tetrahydrofuran. In a $20 \mathrm{~mL}$ vial, $1.82 \mathrm{~g} \mathrm{~L}$-glutamic acid was slowly dissolved in $3 \mathrm{~mL} \mathrm{NaOH}$ aqueous solution $(2 \mathrm{M})$. The ratio of $L$-glutamic acid to 2 methyl-4-(2-methyl propyl) phenylacetyl chloride was set at $0.85: 1.0$ to make sure there is no $L$-glutamic acid left. After mixing the $L$-glutamic acid aqueous solution with 2-methyl4-(2-methyl propyl) phenylacetyl chloride, the mixture was stirred for $8 \mathrm{~h}$. After completing the reaction, the concentrated $\mathrm{HCl}$ was slowly dropped into the reaction system until the solution was acidified to $\mathrm{pH} 1 \sim 3$. A lot of white solids then appeared during the acidification. After filtration, the filtrate separated into two immiscible layers. Tetrahydrofuran in the upper layer was removed by rotating evaporation to get the crude product. The purified N-2-methyl-4-(2-methyl propyl) phenylacetyl-glutamic acid (MMPPG) was obtained via first washing with petroleum ether and subsequent washing with ether. The reaction about synthesis of MMPPG was shown in Figure 1.

2.3.3. Preparation of Polymer Carriers PIGB, PIGH, and PIGA. In a typical synthesis, $0.335 \mathrm{~g} \mathrm{MMPPG}(0.001 \mathrm{~mol})$ and 1,6 -hexanediol $0.118 \mathrm{~g}(0.001 \mathrm{~mol})$ were added in a $50 \mathrm{~mL}$ eggplant-like flask. As a catalyst, $0.10 \mathrm{~g}$ stannous octoate was added to the reaction system and heated to $130^{\circ} \mathrm{C}$ for polycondensation $(6 \mathrm{~h})$. After cooling the reaction system,
$6 \mathrm{~mL}$ dichloromethane was dropped into the flask to dissolve the product. The crude product was obtained by precipitation of dichloromethane solution into $30 \mathrm{~mL}$ petroleum ether. The crude product was redissolved with $4 \mathrm{~mL}$ ethyl acetate, and the solution was dropped into diethyl ether to get light yellow solid powder, poly( $N$-2-methyl-4-(2-methyl propyl) phenylacetyl-glutamic acid-co-1,6-hexanediol) (PIGH). In addition, poly(N-2-methyl-4-(2-methyl propyl) phenylacetyl-glutamic acid-co-1,4-butanediol) (PIGB) and poly(N-2methyl-4-(2-methyl propyl) phenylacetyl-glutamic acid-co6-amino-hexanol) (PIGA) were also synthesized using the methods mentioned above.

\section{Results and Discussion}

3.1. Design for PIGB, PIGH, and PIGA with Pendant Ibuprofen. In this paper, we developed a biodegradable polymeric drug carrier (polyester and polyester-amide) with pendant ibuprofen group by amide linkage. Figure 1 has presented the synthetic routes of PIGB, PIGH, and PIGA from glutamic acid. Firstly, ibuprofen was acylated by thionyl chloride to prepare 2-methyl-4-(2-methyl propyl) phenylacetyl chloride. Then, 2-methyl-4-(2-methyl propyl) phenylacetyl chloride reacted with glutamic acid to produce a monomer, $N$-2-methyl4-(2-methyl propyl) phenylacetyl-glutamic acid (MMPPG). Lastly, polyester (PIGB, PIGH) and polyester-amide (PIGA) were successfully synthesized by melting polycondensation of MMPPG with 1,4-butanediol, 1,6-hexanediol, and 6-amino hexanol, respectively. In other words, ibuprofen molecule is directly connected with PIGB, PIGH, and PIGA as pendant group, which leads to the higher drug-loading capacity. The liable esters or amides in their main-chains are used as the potential fracture point via biodegradation, avoiding longtime residual of these polymer carriers in human body after drug release.

3.2. Structural Characterization of Monomers and Polymers. In this investigation, the chemical structures of PIGB, PIGH, and PIGA were confirmed by ${ }^{1} \mathrm{H}$ NMR, FTIR spectrum, and GPC. As indicated in Figure 2, PIGB, PIGH, and PIGA can show some characteristic peaks in FTIR spectra confirming presence of ester, amide groups, and benzene rings. For the representative FTIR spectrum of PIGH, the stretching vibration and deforming vibration of $\mathrm{N}-\mathrm{H}$ linkage in the amide group are recorded at 3306 and $1535 \mathrm{~cm}^{-1}$. The characteristic peaks at 1652 and $1737 \mathrm{~cm}^{-1}$ are attributed to the stretching vibration of carbonyl $(\mathrm{C}=\mathrm{O})$ in the amide and ester groups in PIGH, respectively. Furthermore, the ether linkage (C-O-C) from the ester groups in the PIGH main-chain can be identified at $1176 \mathrm{~cm}^{-1}$, and the stretching vibrations for $\mathrm{CH}, \mathrm{CH}_{2}$, and $\mathrm{CH}_{3}$ in PIGH appear at $2954 \mathrm{~cm}^{-1}$ and $2860 \mathrm{~cm}^{-1}$. Similarly, the characteristic peaks of benzene ring can be found at the vicinity of $3065 \mathrm{~cm}^{-1}$.

Compared with polyesters (PIGB and PIGH), the most obvious structural change of polyester-amide (PIGA) is the two amide groups in the main-chain and pendant group. The peak at $1735 \mathrm{~cm}^{-1}$ belongs to the characteristic absorption of carbonyl $(\mathrm{C}=\mathrm{O})$ in ester group, and the peak at $1650 \mathrm{~cm}^{-1}$ is 


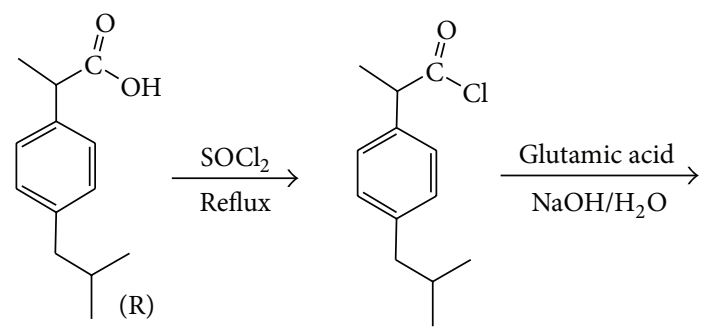<smiles>CCCCCC(C)C(=O)NC(CCC(=O)O)C(=O)O</smiles><smiles>[R]NC(CCC(=O)C(C)(C)C)C(=O)OCCCCOC(C)(C)C</smiles><smiles>[R]NC(CCC(=O)C(C)(C)C)C(=O)OCCCCCCOC(C)(C)C</smiles><smiles>[R]NC(CCC(=O)C(C)(C)C)C(=O)OCCCCCCNC(C)(C)C</smiles>

FIGURE 1: Synthetic routes of polymer carriers PIGB, PIGH, and PIGA.

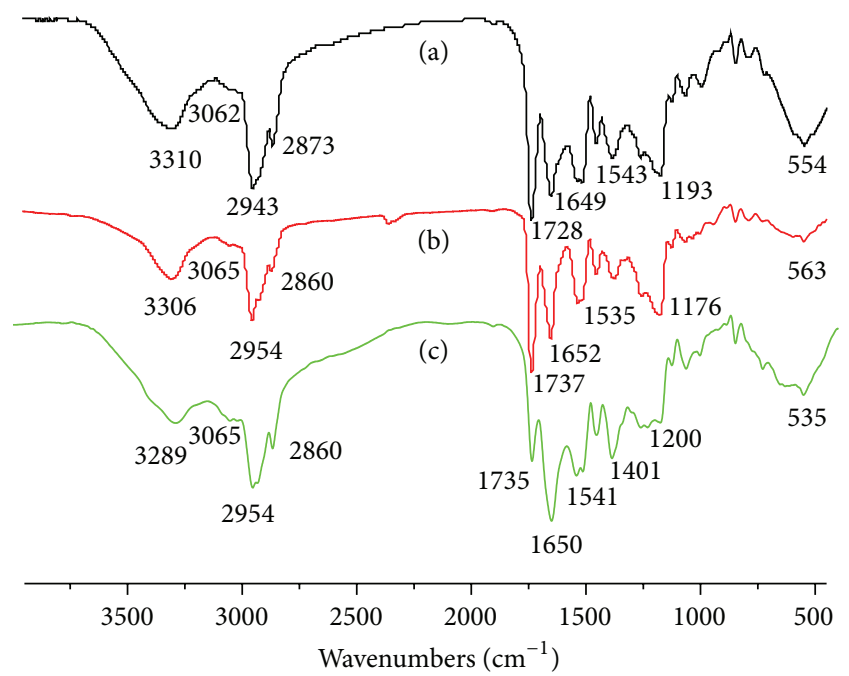

Figure 2: FTIR spectra of PIGB (a), PIGH (b), and PIGA (c).

ascribed to carbonyl $(\mathrm{C}=\mathrm{O})$ in the amide groups of PIGA. Furthermore, the intensity of the peak at $1735 \mathrm{~cm}^{-1}$ is much lower than that at $1650 \mathrm{~cm}^{-1}$, which is different from FTIR of PIGB and PIGH.

The ${ }^{1} \mathrm{H}$ NMR spectra of PIGB, PIGH, and PIGA in deuterated chloroform $\left(\mathrm{CDCl}_{3}\right)$ were shown in Figure 3. For
PIGB, the peaks at 7.11-7.20 ppm $(\mathrm{d}, \mathrm{c})$ are ascribed to four hydrogens from benzene ring of ibuprofen. The characteristic peak at $6.20 \mathrm{ppm}(\mathrm{g})$ can be attributed to $\mathrm{N}-\mathrm{H}$ from amide groups. The peaks of the tertiary carbon $(\mathrm{C}-\mathrm{H})$ appear at $4.55 \mathrm{ppm}(\mathrm{h})$ and $3.58 \mathrm{ppm}(\mathrm{e})$, respectively. Additionally, the absorption peaks of $\mathrm{CH}_{2}$ next to $\mathrm{O}$ atom from 1,4-butanediol are recorded at $4.06 \mathrm{ppm}(\mathrm{k})$. The other two $\mathrm{CH}_{2}$ groups in 1,4-butanediol moiety appear at $1.73 \mathrm{ppm}$ (l). And also, the peaks at $2.22 \mathrm{ppm}$ (j) belong to the characteristic absorption of $\mathrm{CH}_{2}$ groups in $L$-glutamic acid structure. The other peaks in the range of $2.5-0.8 \mathrm{ppm}(\mathrm{a}, \mathrm{b}, \mathrm{f})$ are corresponding to the $\mathrm{CH}, \mathrm{CH}_{2}$, and $\mathrm{CH}_{3}$ groups in ibuprofen moiety. It is necessary to state that ${ }^{1} \mathrm{H}$ NMR spectrum of PIGH is similar to PIGB, and the broad peaks of N-H in PIGA appear at 7.5 8.5 ppm. Based on the abovementioned FTIR and ${ }^{1} \mathrm{H}$ NMR spectra, PIGB, PIGH, and PIGA have been successfully synthesized in our experiment.

According to the structure shown in Figure 1, the content of ibuprofen moiety in synthesized polymer carriers was calculated as $37.7 \%$ for PIGB, 35.2\% for PIGH, and $35.3 \%$ for PIGA, respectively. By the polymeric drug or pendant drug methods, the drug-loading capacity was also greatly increased in some other reported systems such as malic acidbased polyester [28], poly( $\varepsilon$-caprolactone-co-lactide) [29], polyacrylic ibuprofen prodrug [17], ibuprofen carrier from polyethylene glycol [30], and polyethylene-based polymeric prodrugs [16]. 

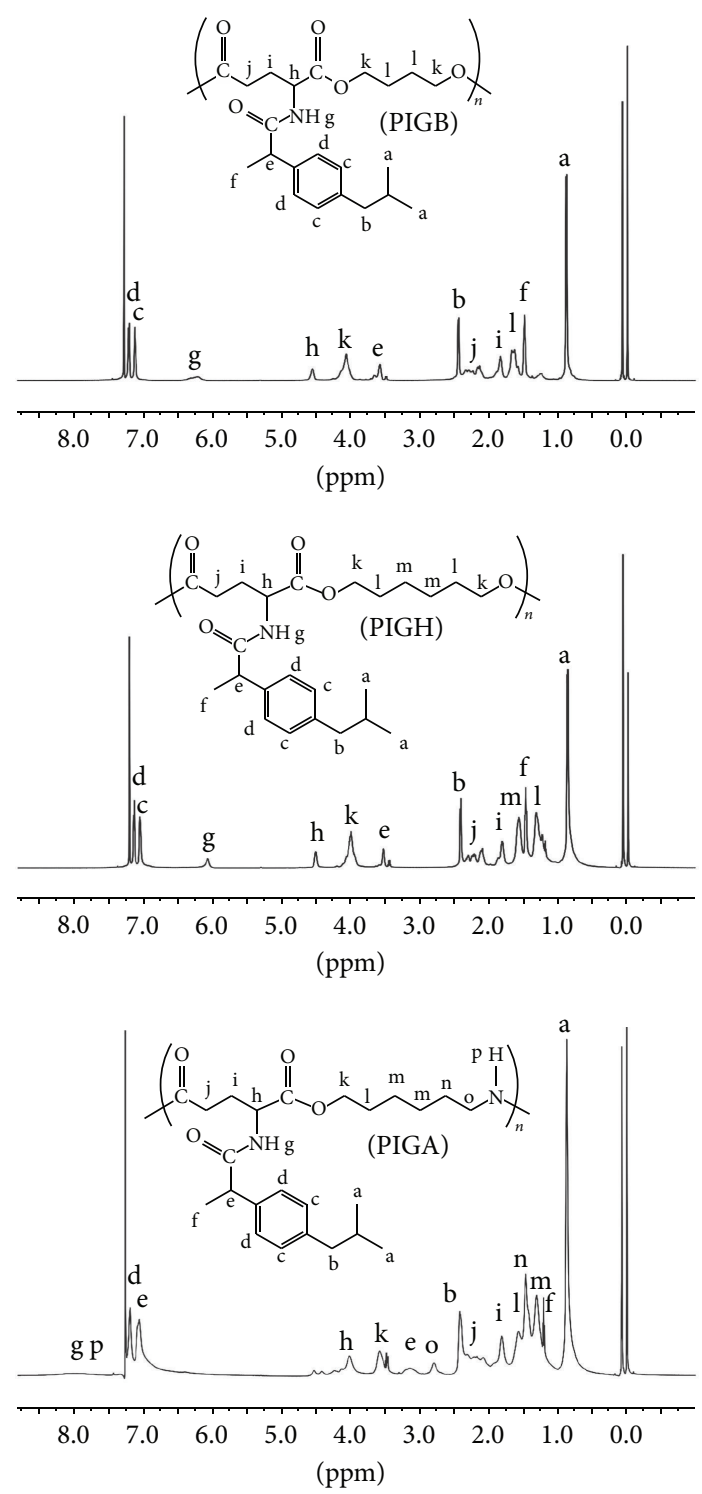

Figure $3:{ }^{1} \mathrm{H}$ NMR spectra of PIGB, PIGH, and PIGA.

In this investigation, the molecular weights of three polymer carriers were measured by GPC measurement with $\mathrm{N}, \mathrm{N}$-dimethylformamide $(0.1 \% \mathrm{LiBr})$ as the eluent. As shown in Figure 4(a), the molecular weights of PIGA, PIGB, and PIGH were $0.82 \times 10^{4} \mathrm{~g} / \mathrm{mol}, 0.87 \times 10^{4} \mathrm{~g} / \mathrm{mol}$, and 0.75 $\times 10^{4} \mathrm{~g} / \mathrm{mol}$, and their polydispersity index (PDI) was 1.87 , 2.22 , and 1.96 , respectively. In addition, the contact angles measurement was used to confirm the relative hydrophilicity of polymers. Seen from the molecular structure, PIGA is the most hydrophilic compound because of one ester and two amides in the repeating unit, and its contact angle with water should be the smallest one. PIGH is most hydrophobic due to the two esters, one amide and the longer aliphatic chain, and its contact angle with water should be the largest one. As shown in Figure 4(b), the contact angles of PIGA, PIGB, and PIGH were $44^{\circ}, 70^{\circ}$, and $82^{\circ}$ at room temperature, respectively. The experimental results about contact angle measurements were in accordance with the abovementioned theoretical analysis.

3.3. Release Profile of Ibuprofen from PIGB, PIGH, and PIGA. In this investigation, the different release behavior of ibuprofen was observed for polyester-amide (PIGA) and polyesters (PIGB, PIGH). As presented in Figure 5, the amount of ibuprofen released from PIGA chains is much higher than the other two polymers, which is $65 \%$ over $15 \mathrm{~h}$ at the simulated physiological conditions $\left(37^{\circ} \mathrm{C}\right)$. At room temperature $\left(25^{\circ} \mathrm{C}\right)$, the accumulative release of ibuprofen is about $50 \%$ in the same release time. This release difference can be attributed to the fact that the release rate of ibuprofen by the cracking of amide (hydrolyzing) at $37^{\circ} \mathrm{C}$ is faster than that at $25^{\circ} \mathrm{C}$.

Figure 6 indicated the release behaviors of ibuprofen from polyesters PIGB and PIGH in the simulated physiological conditions. For polyesters PIGB and PIGH, the amount of released ibuprofen is $32 \%$ and $27 \%$ at $37^{\circ} \mathrm{C}$ over 10 days, respectively. At $25^{\circ} \mathrm{C}$, the accumulative release of ibuprofen is measured as only $25 \%$ and $18 \%$ for PIGB and PIGH over the same time. For PIGA, PIGB, and PIGH, the ibuprofen is released from these polymer carriers in a controlled manner. In other words, the obvious burst is not observed in the course of ibuprofen release. Compared with polyester-amide (PIGA), the release rate of ibuprofen from polyester (PIGB and PIGH) chain was much slower. For the two polyesters, the ibuprofen release from PIGH is slightly slower than that from PIGB over the same time. Overall, the release rate of ibuprofen from PIGA was the highest and the release rate of ibuprofen from PIGH was the lowest.

The release of ibuprofen molecules was accomplished by the hydrolysis of the amide between ibuprofen and polymer main-chains as shown in Figure 1. The hydrolysis rate is inevitably dependent on the hydrophilicity of the three polymers as PIGA, PIGB, and PIGH carriers suspended in PBS. If the polymer carrier has higher hydrophilicity, water molecule is more conducive to reaction with amide bond, leading to the release of ibuprofen. It is well known that the contact angle is considered as an important reference for hydrophilicity/hydrophobicity of materials. The more hydrophilic the material is, the smaller its contact angle with water is. As shown in Figure 4(b), the contact angles of PIGA, PIGB, and PIGH were measured as $44^{\circ}, 70^{\circ}$, and $82^{\circ}$, respectively. PIGA is the most hydrophilic, PIGB is more hydrophilic, and PIGH was the most hydrophobic. As shown from the results in Figures 5 and 6, the release rate of ibuprofen keeps in accordance with the hydrophilicity of PIGA, PIGB, and PIGH carrier. Therefore, the design and preparation of these polymer carriers also provide a possible method for regulating the release behavior of drug by changing hydrophilicity.

3.4. Cytotoxicity Evaluation for PIGB, PIGH, and PIGA. In order to verify the potential application of PIGB, PIGH, and PIGA, the cytotoxicity of these polymer carriers was determined by MTT (CCK-8) method. HeLa cell used in this study was a common cell in the toxicity evaluation of new biomaterials, and the concentrations of PIGA, PIGB, 


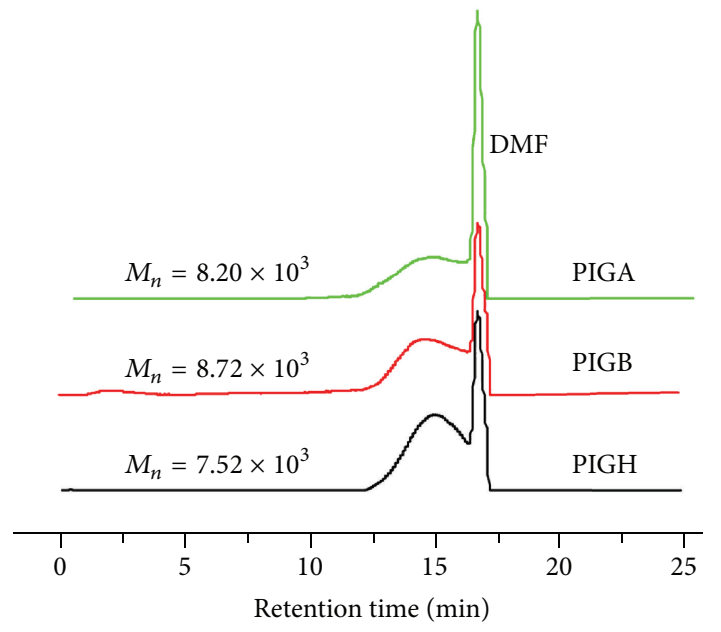

(a)
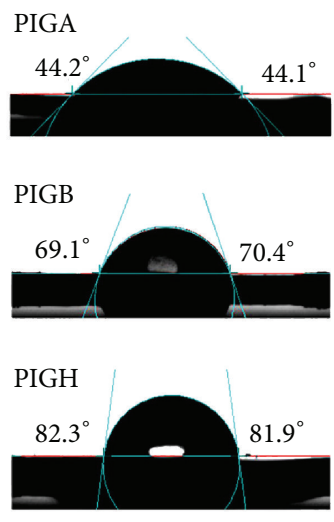

(b)

FIgURE 4: GPC curves (a) and contact angles (b) of PIGA, PIGB, and PIGH.

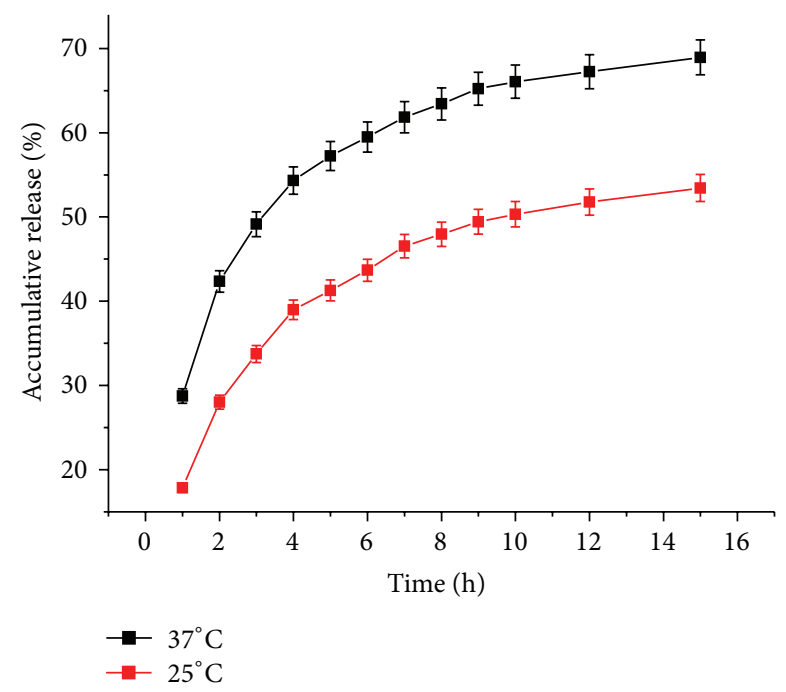

FIGURE 5: The accumulative release of ibuprofen from polyesteramide (PIGA).

and PIGH solutions were $0.01,0.1,1.0,10$, and $100 \mathrm{~g} / \mathrm{mL}$, respectively. After $48 \mathrm{~h}$ incubation, the viability of HeLa cells to PIGB, PIGH, and PIGA carriers reached up to more than $100 \%$ as shown in Figure 7. Besides, HeLa cells showed a normal cell proliferation even as the concentration of polymer solutions varied from $0.01 \mathrm{~g} / \mathrm{mL}$ to $100 \mathrm{~g} / \mathrm{mL}$. These data indicate that PIGB, PIGH, and PIGA with ibuprofen as pendant group are mostly cytocompatible in the tested concentration range.

\section{Conclusion}

In this work, we described the synthesis and characterization of new biodegradable polyester and polyester-amide comprising biocompatible segments, with ibuprofen pendant

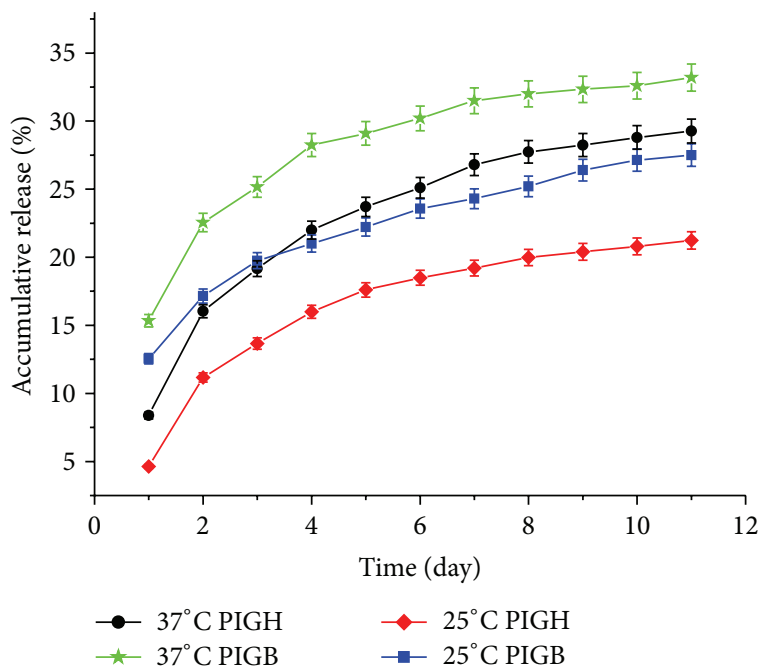

Figure 6: The accumulative release of ibuprofen from polyesters (PIGH and PIGB).

group. Higher loading capacities of ibuprofen are achieved at the amount of $37.7 \%$ for PIGB, 35.2\% for PIGH, and $35.3 \%$ for PIGA, respectively. The released ibuprofen preserves its chemical structure and its release behavior shows a duration mode with no burst. For polyester-amide PIGA, the continuous release of ibuprofen was more than $65 \%$ over $15 \mathrm{~h}$ in the mimicking physiological conditions, while the release of ibuprofen is only $21 \sim 32 \%$ over 10 days from polyesters PIGH and PIGB. The release rate of ibuprofen is facilely regulated by the different hydrophilicity of PIGA, PIGH, and PIGB carriers. Moreover, PIGA, PIGH, and PIGB show no toxicity to HeLa cells by MTT (CCK-8) assay and the viability cells over $48 \mathrm{~h}$ are much higher than $100 \%$. In brief, the preparation and release behaviors of three polymer carriers provide a reference for its application in drug release, especially in 


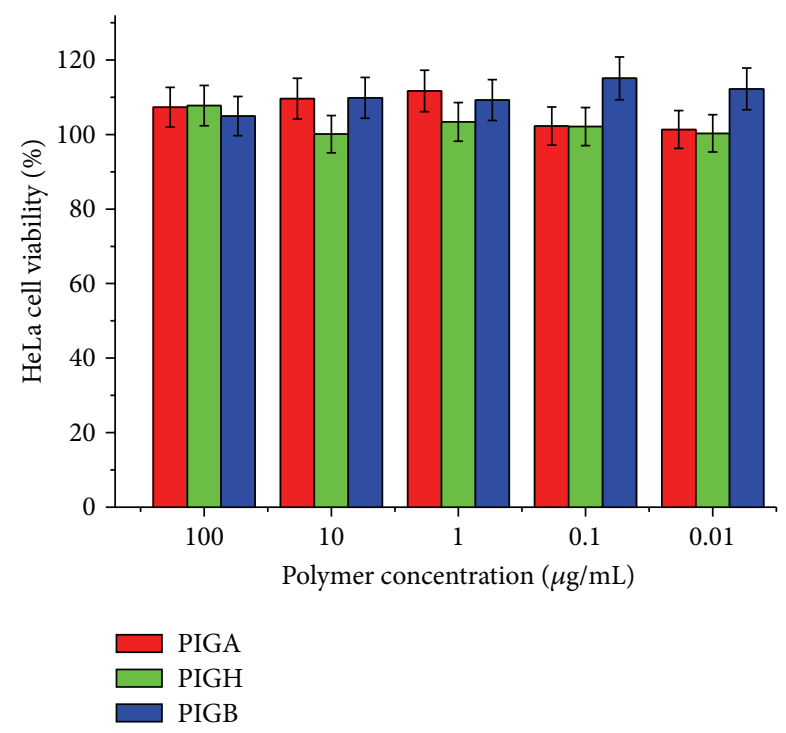

Figure 7: Viability of HeLa cells in different polymers solution over $48 \mathrm{~h}$ incubation.

treating inflammatory diseases and lowering the side-effects of conventional drug.

\section{Competing Interests}

The authors declare that they have no competing interests.

\section{Acknowledgments}

The research was financially supported by Hebei Natural Science Foundation of China (Grant no. B2015201133); Key Project of Hebei Education Department (Grant no. ZD20131047); Training Program for Innovative Research Team and Leading Talent in Hebei Province University (Grant no. LJRC024).

\section{References}

[1] B. J. Crielaard, T. Lammers, R. M. Schiffelers, and G. Storm, "Drug targeting systems for inflammatory disease: one for all, all for one," Journal of Controlled Release, vol. 161, no. 2, pp. 225234, 2012.

[2] J. Braun and J. Sieper, "Ankylosing spondylitis," The Lancet, vol. 369, no. 9570, pp. 1379-1390, 2007.

[3] P. M. Brooks and R. O. Day, "Nonsteroidal antiinflammatory drugs-differences and similarities," The New England Journal of Medicine, vol. 324, no. 24, pp. 1716-1725, 1991.

[4] J. P. Jain, S. Modi, A. J. Domb, and N. Kumar, "Role of polyanhydrides as localized drug carriers," Journal of Controlled Release, vol. 103, no. 3, pp. 541-563, 2005.

[5] M.S. Y. Khan and M. Akhter, "Synthesis, pharmacological activity and hydrolytic behavior of glyceride prodrugs of ibuprofen," European Journal of Medicinal Chemistry, vol. 40, no. 4, pp. 371376, 2005.

[6] B. Mu, W. Zhong, Y. Dong, P. Du, and P. Liu, "Encapsulation of drug microparticles with self-assembled $\mathrm{Fe}_{3} \mathrm{O}_{4}$ /alginate hybrid multilayers for targeted controlled release," Journal of Biomedical Materials Research-Part B Applied Biomaterials, vol. 100, no. 3, pp. 825-831, 2012.

[7] J. W. McGinity, J. C. DiNunzio, and J. M. Keen, "Oral controlledrelease polymeric drug delivery systems," Engineering Polymer Systems for Improved Drug Delivery, vol. 56, pp. 283-318, 2014.

[8] R. A. Bader and D. A. Putnam, "Fundamentals of drug delivery," Engineering Polymer Systems for Improved Drug Delivery, 2013.

[9] L. R. Pires, V. Guarino, M. J. Oliveira et al., "Ibuprofenloaded poly(trimethylene carbonate-co- $\varepsilon$-caprolactone) electrospun fibres for nerve regeneration," Journal of Tissue Engineering and Regenerative Medicine, vol. 10, no. 3, pp. E154-E166, 2016.

[10] R. Zurita, J. Puiggalí, and A. Rodríguez-Galán, "Loading and release of ibuprofen in multi- and monofilament surgical sutures," Macromolecular Bioscience, vol. 6, no. 9, pp. 767-775, 2006.

[11] E. Verraedt, G. Van den Mooter, and J. A. Martens, "Novel amorphous microporous silica spheres for controlled release applications," Journal of Pharmaceutical Sciences, vol. 100, no. 10, pp. 4295-4301, 2011.

[12] A. B. Moustafa, R. A. Sobh, A. M. Rabie, H. E. Nasr, and M. M. H. Ayoub, "Synthesis and in vitro release of guest drugsloaded copolymer nanospheres MMA/HEMA via differential microemulsion polymerization," Journal of Applied Polymer Science, vol. 129, no. 2, pp. 853-865, 2013.

[13] S. H. Oh, J. K. Kim, K. S. Song et al., "Prevention of postsurgical tissue adhesion by anti-inflammatory drug-loaded pluronic mixtures with sol-gel transition behavior," Journal of Biomedical Materials Research Part A, vol. 72, no. 3, pp. 306-316, 2005.

[14] S. H. Emami, Z. H. Pirbasti, M. M. Hasani-Sadrabadi, and S. S. Kordestani, "The effect of isopropanol addition on enhancement of transdermal controlled release of ibuprofen from ethylene vinyl acetate copolymer membranes," Journal of Applied Polymer Science, vol. 122, no. 5, pp. 3048-3054, 2011.

[15] M. Feng and P. Li, "Amine-containing core-shell nanoparticles as potential drug carriers for intracellular delivery," Journal of Biomedical Materials Research Part A, vol. 80, no. 1, pp. 184-193, 2007.

[16] J. K. Leonard, D. Turek, K. B. Sloan, and K. B. Wagener, "Polyethylene prodrugs using precisely placed pharmaceutical agents," Macromolecular Chemistry and Physics, vol. 211, no. 2, pp. 154-165, 2010.

[17] R. París, J. M. García, and I. Quijada-Garrido, "Synthesis and characterization of a new acrylic polymeric ibuprofen prodrug," Journal of Applied Polymer Science, vol. 117, no. 6, pp. 3271-3276, 2010.

[18] P. Andrade-Vivero, E. Fernandez-Gabriel, C. Alvarez-Lorenzo, and A. Concheiro, "Improving the loading and release of NSAIDs from pHEMA hydrogels by copolymerization with functionalized monomers," Journal of Pharmaceutical Sciences, vol. 96, no. 4, pp. 802-813, 2007.

[19] J. Han, J. Sun, S. Bai, H. Panezai, X. Jin, and X. Wu, "Graft to synthesis and ibuprofen-loading performance of $\mathrm{pH}$-sensitive PMAA-silica hybrid nanoparticles with controlled bimodal mesopores," Journal of Pharmaceutical Sciences, vol. 104, no. 12, pp. 4299-4306, 2015.

[20] J.-T. Zhang, S.-W. Huang, J. Liu, and R.-X. Zhuo, "Temperature sensitive poly[ $N$-isopropylacrylamide-co-(acryloyl $\beta$ cyclodextrin)] for improved drug release," Macromolecular Bioscience, vol. 5, no. 3, pp. 192-196, 2005. 
[21] J. X. Zhang, L. Y. Qiu, X. L. Wu, Y. Jin, and K. J. Zhu, "Temperature-triggered nanosphere formation through selfassembly of amphiphilic polyphosphazene," Macromolecular Chemistry and Physics, vol. 207, no. 14, pp. 1289-1296, 2006.

[22] D.-G. Yu, X.-F. Zhang, X.-X. Shen, C. Brandford-White, and L.-M. Zhu, "Ultrafine ibuprofen-loaded polyvinylpyrrolidone fiber mats using electrospinning," Polymer International, vol. 58, no. 9, pp. 1010-1013, 2009.

[23] H. Jia and L. L. Kerr, "Sustained ibuprofen release using composite poly(lactic-co-glycolic acid)/titanium dioxide nanotubes from Ti implant surface," Journal of Pharmaceutical Sciences, vol. 102, no. 7, pp. 2341-2348, 2013.

[24] M. Lin, S. Meng, W. Zhong, Z. Li, Q. Du, and P. Tomasik, "Novel biodegradable blend matrices for controlled drug release," Journal of Pharmaceutical Sciences, vol. 97, no. 10, pp. 42404248, 2008.

[25] L. J. del Valle, D. Roca, L. Franco, J. Puiggalí, and A. RodríguezGalán, "Preparation and release study of ibuprofen-loaded porous matrices of a biodegradable poly(ester amide) derived from L-alanine units," Journal of Applied Polymer Science, vol. 122, no. 3, pp. 1953-1967, 2011.

[26] R. Rosario-Meléndez, W. Yu, and K. E. Uhrich, "Biodegradable polyesters containing ibuprofen and naproxen as pendant groups," Biomacromolecules, vol. 14, no. 10, pp. 3542-3548, 2013.

[27] I. Cantón, R. Mckean, M. Charnley et al., "Development of an Ibuprofen-releasing biodegradable PLA/PGA electrospun scaffold for tissue regeneration," Biotechnology and Bioengineering, vol. 105, no. 2, pp. 396-408, 2010.

[28] N. D. Stebbins, W. Yu, and K. E. Uhrich, "Enzymatic polymerization of an ibuprofen-containing monomer and subsequent drug release," Macromolecular Bioscience, vol. 15, no. 8, pp. 11151124, 2015.

[29] C. Wu, J. Xie, C. Branford-White, J. Quan, and L. Zhu, “In vitro controlled release of polymeric drug-saccharide conjugates with ketoprofen, ibuprofen, and naproxen pendants," Journal of Applied Polymer Science, vol. 121, no. 3, pp. 1654-1660, 2011.

[30] S. Davaran, M. R. Rashidi, and M. Hashemi, "Synthesis and hydrolytic behaviour of 2-mercaptoethyl ibuprofenatepolyethylene glycol conjugate as a novel transdermal prodrug," Journal of Pharmacy and Pharmacology, vol. 55, no. 4, pp. 513$517,2003$. 

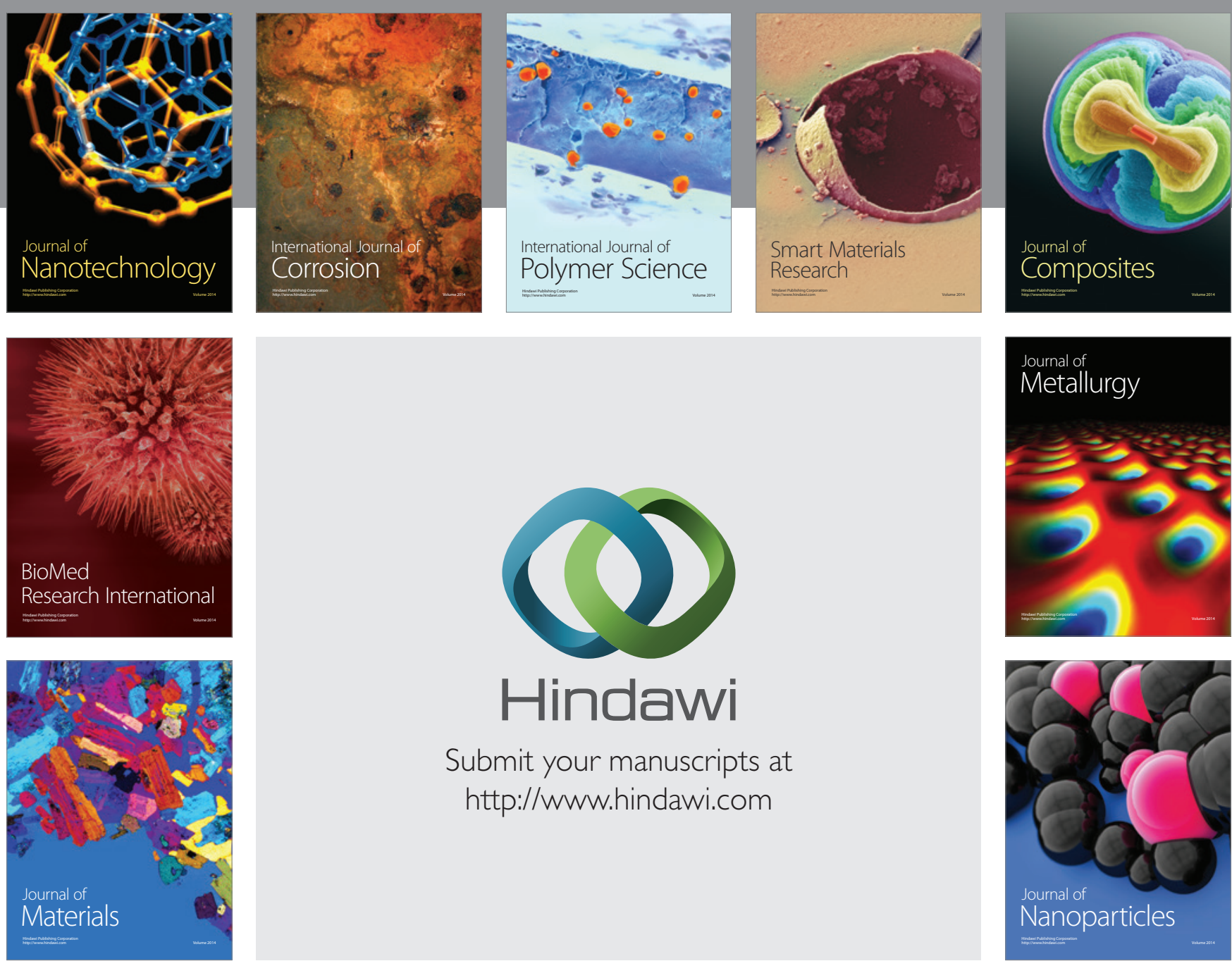

\section{Hindawi}

Submit your manuscripts at

http://www.hindawi.com

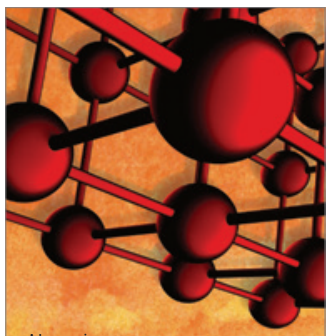

Materials Science and Engineering
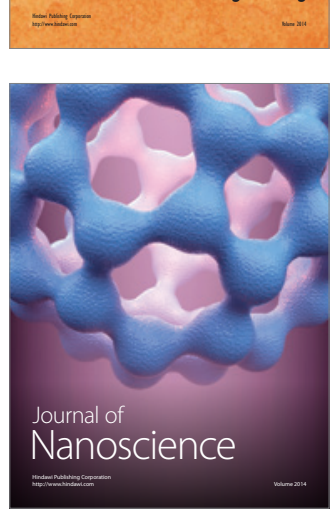
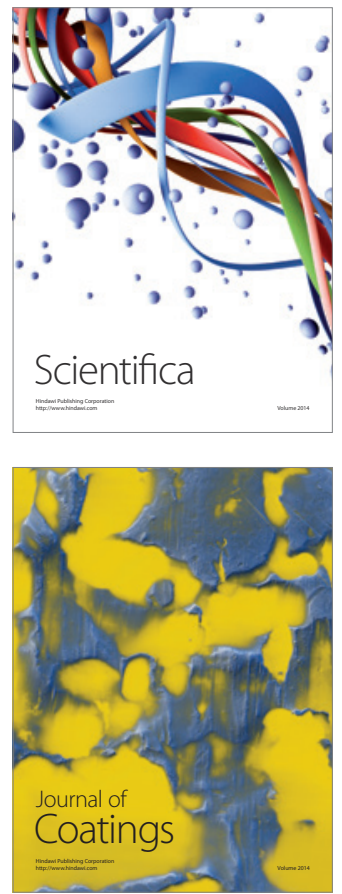
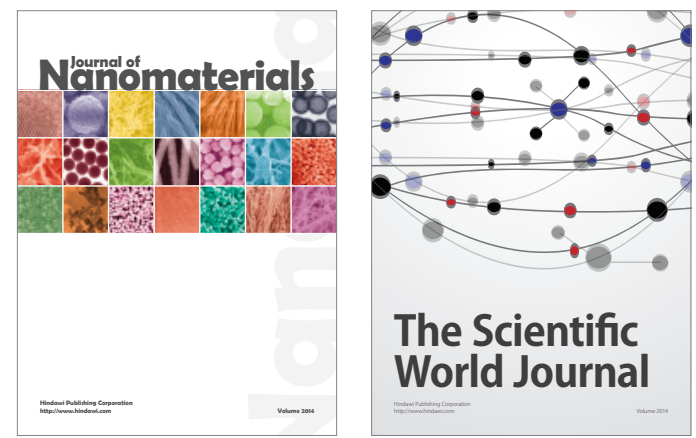

The Scientific World Journal
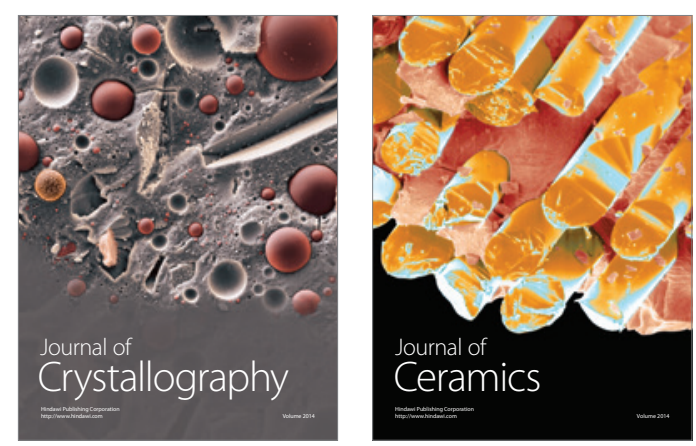
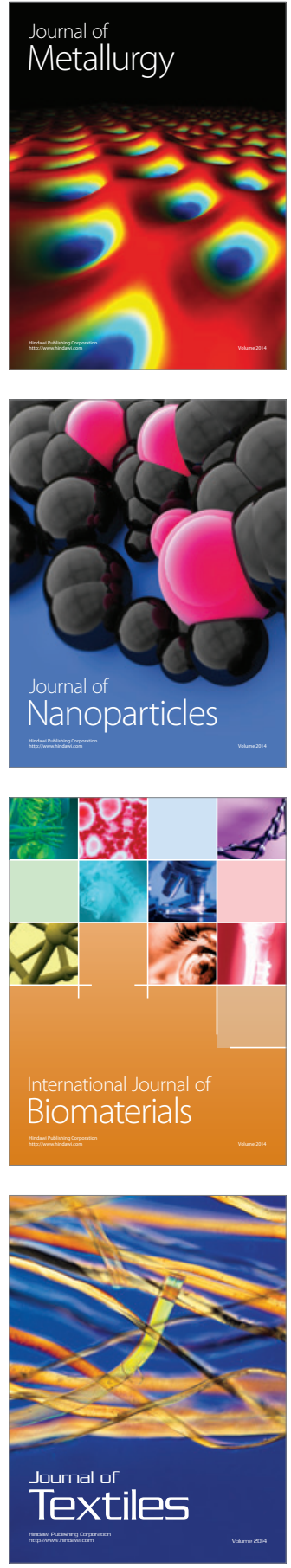